\title{
openheart Impact of proctoring on success rates for percutaneous revascularisation of coronary chronic total occlusions
}

\author{
Vinoda Sharma, ${ }^{1}$ S T Jadhav, ${ }^{1}$ A A Harcombe, ${ }^{1}$ P A Kelly, ${ }^{2}$ A Mozid, ${ }^{2}$ A Bagnall, ${ }^{3}$ \\ J Richardson, ${ }^{3}$ M Egred, ${ }^{3}$ M McEntegart, ${ }^{4}$ A Shaukat, ${ }^{4} \mathrm{~K}$ Oldroyd, ${ }^{4}$ \\ G Vishwanathan, ${ }^{5} \mathrm{O}$ Rana, ${ }^{5} \mathrm{~S}$ Talwar, ${ }^{5} \mathrm{M}$ McPherson, ${ }^{6} \mathrm{~J}$ W Strange, ${ }^{7}$ \\ C G Hanratty, ${ }^{8}$ S J Walsh, ${ }^{8} \mathrm{~J} \mathrm{C} \mathrm{Spratt,}{ }^{6}$ W H T Smith ${ }^{1}$
}

To cite: Sharma V, Jadhav ST, Harcombe AA, et al. Impact of proctoring on success rates for percutaneous revascularisation of coronary chronic total occlusions. Open Heart 2015;2:e000228. doi:10.1136/openhrt-2014000228

Received 3 December 2014 Revised 30 January 2015 Accepted 4 March 2015
CrossMark

For numbered affiliations see end of article.

Correspondence to Dr WHT Smith;

William.Smith@nuh.nhs.uk

\section{ABSTRACT}

Objective: To assess the impact of proctoring for chronic total occlusion (CTO) percutaneous coronary intervention (PCl) in six UK centres.

Methods: We retrospectively analysed 587 СТO procedures from six UK centres and compared success rates of operators who had received proctorship with success rates of the same operators before proctorship (pre-proctored) and operators in the same institutions who had not been proctored (non-proctored). There were 232 patients in the pre-proctored/non-proctored group and 355 patients in the post-proctored group. Complexity was assessed by calculating the Japanese CTO (JCTO) score for each case.

Results: CTO PCl success was greater in the postproctored compared with the pre-proctored/nonproctored group $(77.5 \%$ vs $62.1 \%, p<0.0001)$. In more complex cases where $\mathrm{JCTO} \geq 2$, the difference in success was greater $(70.7 \%$ vs $49.5 \%, p=0.0003)$. After proctoring, there was an increase in CTO PCl activity in centres from $2.5 \%$ to $3.5 \%, p<0.0001$ (as a proportion of total $\mathrm{PCl}$ ), and the proportion of very difficult cases with JCTO score $\geq 3$ increased from $15.3 \%(35 / 229)$ to $29.7 \%$ (105/354), $p<0.0001$. Conclusions: Proctoring resulted in an increase in procedural success for CTO $\mathrm{PCl}$, an increase in complex CTO PCl and an increase in total CTO PCI activity. Proctoring may be a valuable way to improve access to CTO PCl and the likelihood of procedural success.

\section{INTRODUCTION}

Success rates for chronic total occlusion (CTO) percutaneous coronary intervention (PCI) in published series have increased by an average of $1 \%$ per year from $68 \%$ in 2000 to $79 \%$ by $2011 .{ }^{1}$ The impact of any development on success rate may be reduced by the tendency for operators to take on more challenging cases. ${ }^{2}$ However, in the absence of an increase in CTO PCI as a proportion of total PCI activity in national registries, it

\section{KEY MESSAGES}

What is already known about this subject?

- Although high success rates for chronic total occlusion (CTO) percutaneous coronary intervention $(\mathrm{PCl})$ have been reported in small series, these have proved challenging to reproduce in broader populations.

- A systematic approach to angiographic assessment and procedural strategy termed the hybrid approach has been associated with high procedural success.

- The hybrid approach requires training in antegrade wire escalation, antegrade dissection re-entry and the retrograde approach.

What does this study add?

- Before engagement in a systematic training programme, there is evidence of case selection bias with low levels of procedural success evident in more complex cases.

- Following engagement in a training programme, which included one-to-one proctoring, we identified a large increase in CTO PCI success in six UK interventional units.

- The increase in success is greatest in the most complex cases. Following proctorship, there was less suggestion of selection bias with an increase in case complexity and with CTO PCI activity representing a higher proportion of total $\mathrm{PCl}$ activity.

How might this impact on clinical practice?

- Our data support engagement in a systematic training programme for CTO $\mathrm{PCl}$, which includes onsite proctoring.

- Referral of 'complex' CTOs to a dedicated СТO service with operators proficient in retrograde and antegrade dissection re-entry techniques is likely to offer better procedural success, particularly in more complex cases.

seems unlikely that there has been a widespread increase in case complexity in the last decade. There are large differences in 
attempt rates between centres performing CTO PCI, which are difficult to resolve scientifically and which may reflect variation in operator expertise. ${ }^{3}$ The Japanese CTO (JCTO) score provides the most widely accepted measure of technical complexity, but has been recently introduced and is not routinely recorded in most registries. ${ }^{4}$ As case complexity increases, conventional wire techniques become less successful and less efficient, ${ }^{5}$ with a consequently higher need for retrograde techniques and techniques which use blunt dissection to negotiate long, tortuous or calcified occlusions. ${ }^{6}$ The relative complexity of these methods and previous lack of a systematic approach to CTO PCI may explain why these techniques have remained concentrated in the hands of a limited number of CTO experts.

The hybrid approach to CTO PCI is a novel, systematic, algorithm-led PCI strategy based on the identification of key angiographic features and the ability to utilise newer PCI approaches, including antegrade dissection re-entry (ADR) and retrograde dissection re-entry (RDR) techniques. ${ }^{7}$ The algorithm was designed to be easily teachable and reproducible, contrasting with traditional wire-based approaches, which rely on individual operator skill and 'feel'. To ensure appropriate use, access to dedicated dissection re-entry devices (Crossboss; Stingray; Boston Scientific, USA) has been restricted to centres that have engaged in a training programme. We aimed to assess the impact of this by retrospective analysis of success rates for CTO PCI in six UK centres, Glasgow, Newcastle, Bristol, Bournemouth, Essex and Nottingham, before and after their engagement in this training programme.

\section{METHODS}

All centres received a minimum of three proctoring visits with some operators visiting their proctor's centre for additional experience. Proctors were expert CTO PCI operators with a career experience of over 750 CTO PCI procedures, including over 100 retrograde and 100 ADR cases. When proctors visited, cases were scheduled to allow sufficient time with alternative cover arranged for emergency cases. ${ }^{8}$ All participating operators were experienced interventional cardiologists in practice for a median of 8 years undertaking a median of 325 PCI cases annually. All operators attended at least 2 days of didactic teaching and live case review and were encouraged to visit a website containing source material and case studies (http://www.ctofundamentals.org). A systematic audit of all CTO procedures in these centres was undertaken over periods of 6-12 months before and after periods of proctoring. Cases undertaken jointly with the proctors were not included. Cases were identified from data routinely reported to the British Cardiovascular Intervention Society (BCIS) national database as CTOs and validated by review of the angiograms and clinical records. Cases not meeting the criteria for 'true' or 'functional' occlusion, or whose occlusion was likely to have been in the past 3 months, were excluded.
Pooled patient level data including technique used in CTO PCI for sequential patients who underwent CTO PCI at these six different Cardiology centres were analysed.

Operators were described as 'post-proctored' after they had undertaken CTO PCI jointly with a proctor as part of a training programme in hybrid CTO PCI and 'pre-proctored' before they had done so. Operators were described as 'non-proctored' if they had never been proctored by an expert in CTO PCI. Patients were divided into two 'groups' based on whether the operator was pre-proctored/non-proctored or post-proctored.

The JCTO score was calculated for all cases by an independent observer, not the operator. The successful strategy was categorised as antegrade wire escalation (AWE), ADR (either with knuckle wire and wire-based re-entry or dedicated device, eg, CrossBoss and Stingray) or retrograde (Retro-either retrograde wire escalation or RDR).

\section{Statistical analysis}

Statistical analysis was performed using SPSS V.20. Missing values for demographic variables were replaced by median of the nearest neighbour. No variable had missing values $>5 \%$. Demographics, success rates and techniques were compared between the two groups. Continuous variables are presented as mean $( \pm \mathrm{SD})$ and categorical variables as percentage. The $\chi^{2}$ test or Fisher's exact test was utilised for testing the difference between categorical variables and Student $t$ test for assessing the difference between means. Results were considered statistically significant if $\mathrm{p}$ was $<0.05$.

A propensity score was derived by modelling a logistic regression analysis with 'proctored or not' as the dependent variable and the following factors as indicators: age, gender, diabetes mellitus, hypertension, hypercholesterolaemia, smoker, renal impairment (creatinine $>200 \mu \mathrm{mol} / \mathrm{L}$ ), previous coronary artery bypass grafting (CABG), previous cerebrovascular event, objective evidence of ischaemia, presenting clinical syndrome (stable angina), previous failed CTO PCI, radial access, dual access, use of newer tools (CrossBoss, Stingray, Tornus or Corsair Microcatheter), retrograde approach and the JCTO score ( $\geq 2$ or not). This derived propensity score was used as a variable along with 'has been proctored' as a second variable in a regression (covariance) adjustment to adjust for confounding factors and identify predictors of PCI success. In addition, cross tabulation was undertaken to demonstrate association between proctoring and PCI success by JCTO scores.

\section{RESULTS}

A total of 587 patients with true CTOs were included in the analysis. In total, 232 patients were in the nonproctored/pre-proctored group and 355 patients in the post-proctored group. Limited technical details were available for three patients in the pre-proctored/non- 
proctored group and one patient in the post-proctored group.

In total, $19.4 \%$ of total patients were female and $22.5 \%$ had diabetes mellitus. Other demographics and procedural characteristics are illustrated in table 1.

The proctored group had significantly more overall success compared with the pre-proctored/non-proctored group $(77.5 \%$ vs $62.1 \%$, respectively, $\mathrm{p}<0.0001)$. This was driven mainly by an increase in success rate in patients with JCTO scores $\geq 2(70.7 \%$ vs $49.5 \%$, $\mathrm{p}=0.0003$, respectively, figure 1). Success in patients where an attempt at PCI had previously been unsuccessful was $75 \%$ in the post-proctored group and $44 \%$ in the pre-proctored/ non-proctored group $(\mathrm{p}=0.004)$.

Very similar demographics were observed in the two 'groups' but there were a higher proportion of patients with a history of CABG (16.3\% vs $9.5 \%, \mathrm{p}=0.019)$ and previous failure $(29.4 \%$ vs $11.6 \%, \mathrm{p}=0.019)$ in the postproctored group. The proportion of lesions with JCTO scores $\geq 3$ and $\geq 4$ was significantly greater in the postproctored group (table 2).

Proctoring was a significant indicator of CTO PCI success as demonstrated by regression analysis $(\mathrm{OR}=0.47$, $\mathrm{p}<0.001,95 \%$ CI $(0.33$ to 0.67$))$. Cross tabs demonstrated a moderate but significant association of PCI success if the operator had been proctored, especially in patients with JCTO scores $\geq 2$ (Phi, Cramer's V and
Contingency coefficient all $>0.2$ ). In the post-proctored period, the amount of CTO PCI as a proportion of each centre's total PCI activity increased from $2.5 \%$ to $3.5 \%$ $(\mathrm{p}<0.0001$, table 3$)$.

Procedures in the post-proctoring group had higher radiation doses (16 $\left.386 \mathrm{vs} 10400.5 \mathrm{cGy} / \mathrm{m}^{2}, \mathrm{p}<0.0001\right)$ and greater contrast use (299 vs $254 \mathrm{~mL}, \mathrm{p}<0.0001$; table 1 ).

There was no significant difference in complications recorded in between the two groups (table 4).

\section{DISCUSSION}

We report the first systematic attempt to identify the impact of a dedicated teaching programme and a novel treatment algorithm on case selection and subsequent procedural success in CTO PCI. Technical success for CTO PCI increased after proctoring from a mean of $62-78 \%$ at the six centres.

Concurrently, the case mix evolved such that significantly more difficult CTOs were treated, including a greater proportion of patients with prior CABG, a factor which has previously been associated with lower procedural success. ${ }^{9}$ Furthermore, we observed an increase in the total proportion of CTO PCI being undertaken in contrast to national trends during the same period. These observations are consistent with CTO operators undertaking greater numbers of unselected cases, yet

Table 1 Demographics and CTO PCI details

\begin{tabular}{|c|c|c|c|}
\hline Variable & $\begin{array}{l}\text { Pre-proctored/ } \\
\text { non-proctored group } \\
\mathrm{N}=232\end{array}$ & $\begin{array}{l}\text { Post-proctored } \\
\text { group } \\
\mathrm{N}=355\end{array}$ & $\begin{array}{l}\text { Significance } \\
\text { (p Value) }\end{array}$ \\
\hline Age (mean $\pm S D)$ & $65 \pm 11.55$ & $65 \pm 11.36$ & 1.00 \\
\hline Female gender (\%) & $51(22 \%)$ & $63(17.7 \%)$ & 0.24 \\
\hline HTN (\%) & $164(70.7 \%)$ & $246(69.3 \%)$ & 0.78 \\
\hline DM (\%) & $52(22.4 \%)$ & $80(22.5 \%)$ & 1.00 \\
\hline Hypercholesterolaemia (\%) & $81(34.9 \%)$ & $107(30.1 \%)$ & 0.24 \\
\hline Previous CVA (\%) & $15(6.5 \%)$ & $19(5.4 \%)$ & 0.47 \\
\hline Previous CABG (\%) & $22(9.5 \%)$ & $58(16.3 \%)$ & 0.019 \\
\hline Renal impairment (creatinine $\geq 200 \mathrm{mmol} / \mathrm{L}$ ) (\%) & $4(1.7 \%)$ & $9(2.5 \%)$ & 0.58 \\
\hline Smoker (\%) & $76(32.7 \%)$ & $118(33.2 \%)$ & 0.92 \\
\hline Stable angina (\%) & $188(81 \%)$ & $316(89 \%)$ & 0.008 \\
\hline Success overall (\%) & $144 / 232(62.1 \%)$ & $275 / 355$ (77.5\%) & $<0.0001$ \\
\hline $\mathrm{JCTO} \geq 2 *(\%)$ & $115 / 229(50.2 \%)$ & $205 / 354$ (57.9\%) & 0.07 \\
\hline Success in JCTO $\geq 2(\%)$ & $57 / 115(49.6 \%)$ & 145/205 (70.7\%) & 0.0003 \\
\hline Previous CTO PCI failure (\%) & $27(11.6 \%)$ & $104(29.3 \%)$ & $<0.001$ \\
\hline Success in previous failure & $12 / 27(44.4 \%)$ & $78 / 104(75 \%)$ & 0.004 \\
\hline Complications (\%) & $15 / 232(6.5 \%)$ & $30 / 354(8.5 \%)$ & 0.42 \\
\hline Dual access (\%) & $67 / 232(28.9 \%)$ & $242 / 355(68.2 \%)$ & $<0.0001$ \\
\hline Contrast load $(\mathrm{mL})^{*}$ & $254 \pm 105.8 \dagger$ & $299 \pm 118.4 \dagger$ & $<0.0001$ \\
\hline Fluoroscopy dose $\left(c G y / m^{2}\right)^{*}$ & $10400.5 \pm 7589.32 \ddagger$ & $16386.1 \pm 19750.8 \ddagger$ & $<0.0001$ \\
\hline Screening time $(\min )^{\star}$ & $39.06 \pm 18.45 \S$ & $42.28 \pm 25.07 \S$ & 0.096 \\
\hline \multicolumn{4}{|c|}{$\begin{array}{l}\text { *Missing values not replaced. } \\
\text { †Data for } 228 \text { patients in non-proctored/pre-proctored and } 346 \text { patients in proctored group. } \\
\text { †Data for } 228 \text { non-proctored/pre-proctored and } 342 \text { post-proctored patients. } \\
\text { §Data for } 229 \text { pre-proctored/non-proctored and } 343 \text { post-proctored patients. } \\
\text { CABG, coronary artery bypass grafting; CTO, chronic total occlusion; CVA, cerebrovascular accident; DM, diabetes mellitus; HTN, } \\
\text { hypertension; JCTO, Japanese CTO; PCI, percutaneous coronary intervention. }\end{array}$} \\
\hline
\end{tabular}




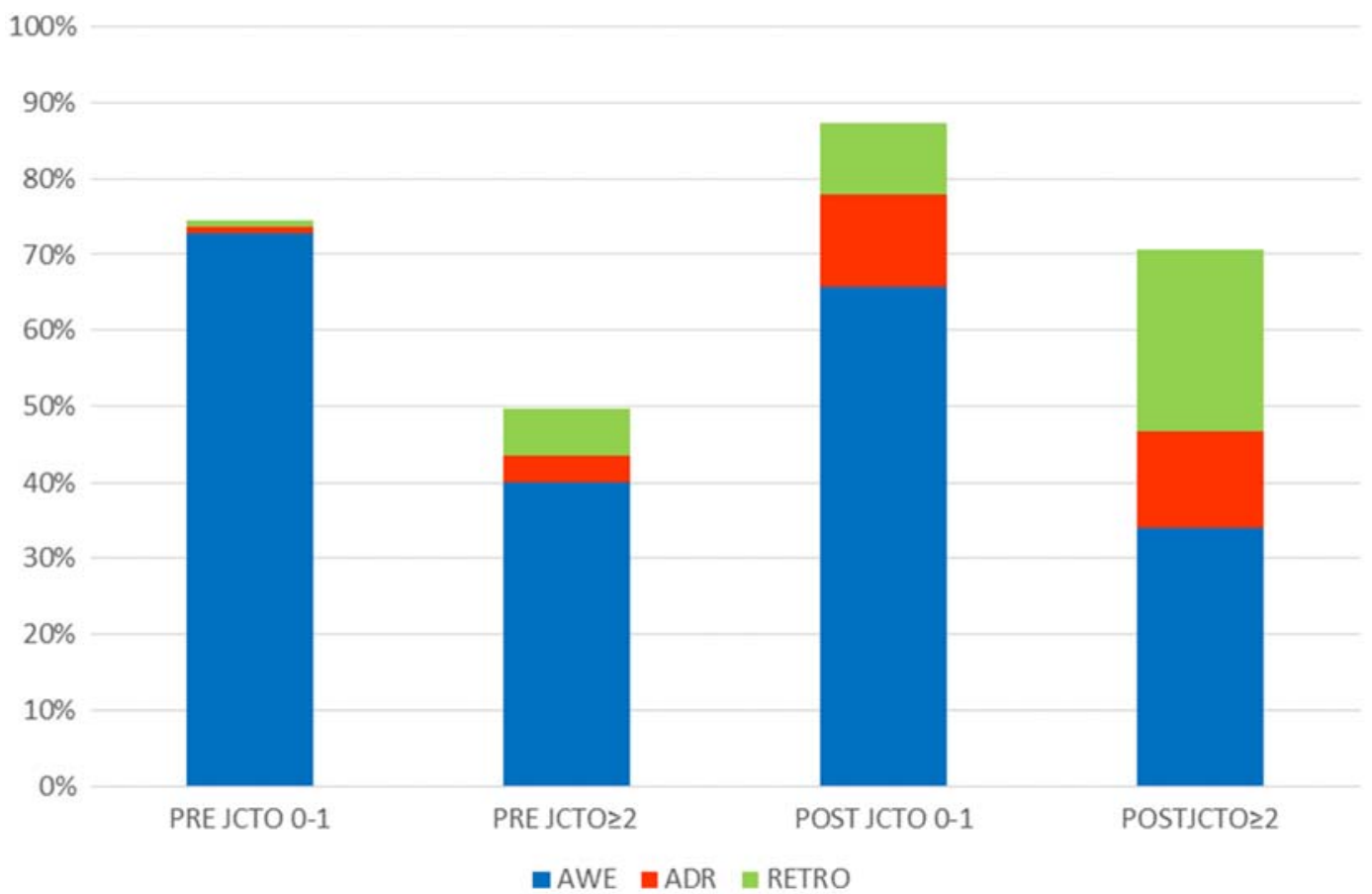

Figure 1 Success rates for procedures undertaken by pre-proctored/non-proctored and post-proctored operators categorised according to JCTO score. JCTO score $0 / 1$ implies easy or moderate and JCTO score $\geq 2$ implies difficult or very difficult. In each bar successful procedures are further categorised by final successful strategy. The proctored group had significantly more overall success compared with the pre-proctored/non-proctored group $(77.5 \%$ vs $62.1 \%$, respectively, $\mathrm{p}<0.0001)$. This was driven mainly by an increase in success rate in patients with $\mathrm{JCTO} \geq 2(70.7 \%$ vs $49.5 \%, \mathrm{p}=0.0003)$. JCTO, Japanese chronic total occlusion; AWE, antegrade wire escalation; ADR, antegrade dissection re-entry; RETRO, retrograde.

delivering higher procedural success after proctoring. The improvement in technical success following proctoring is greatest in more complex CTO PCI cases (JCTO score $\geq 2$ ), where a $21 \%$ greater success rate was found. Lesion complexity is a strong marker for increased CTO crossing time, decreased success rates ${ }^{4}$ and need for blunt dissection techniques whether from an antegrade or retrograde direction..$^{6}$ In less complex lesions, AWE is more likely to be successful as a primary strategy, and as these techniques are most analogous to standard PCI, success rates are generally 'better' with less room for improvement. Despite this, a significant effect was identified.

Perhaps, the greatest difference in success rates is seen in cases where there has been a previous failure. In this category of lesion, proctored operators experienced a

\begin{tabular}{|c|c|c|c|}
\hline $\begin{array}{l}\text { JCTO } \\
\text { score }\end{array}$ & $\begin{array}{l}\text { Pre-proctored/ } \\
\text { non-proctored }\end{array}$ & Post-proctored & Significance \\
\hline$\geq 2$ & $115 / 229(50.2 \%)$ & $205 / 354$ (57.9\%) & 0.07 \\
\hline$\geq 3$ & $35 / 229(15.3 \%)$ & $105 / 354(29.7 \%)$ & $<0.0001$ \\
\hline$\geq 4$ & $5 / 229(2.2 \%)$ & 42/354 (11.9\%) & $<0.0001$ \\
\hline$=5$ & $1 / 229(0.4 \%)$ & $6 / 354(1.7 \%)$ & 0.3 \\
\hline
\end{tabular}

success rate $31 \%$ higher than the non-proctored/preproctored operators. The majority of first attempts are with $\mathrm{AWE}$, and therefore, the availability of another strategy in these cases is particularly helpful, as factors predisposing to failure using this technique often remain present at the time of a subsequent procedure.

It would be simplistic to assert that proctoring in isolation is sufficient to achieve this degree of improvement in success. Concurrent with proctoring, our centres gained access to new devices and the hybrid approach to CTO PCI was becoming more widely accepted. Although the desire to use the CrossBoss and Stingray dissection re-entry devices may have been the stimulus to engage with a proctor, it is important to note that proctoring for CTO PCI has not been based on a particular 'device', but rather the integration of a number of enabling techniques and technologies. ${ }^{10}$ Operators and centres who organised proctoring also had a particular interest in developing CTO programmes and prior to proctoring attended specialist meetings and used other online educational resources. Nevertheless, such educational opportunities have been available for many years without such a marked improvement in success. It is therefore likely that for those with significant pre-existing experience and knowledge, the proctoring visits act to consolidate learning and facilitate the transition from knowledge to practice. The relative effects of proctoring versus technology and theoretical knowledge are most readily separated in 
Table $3 \mathrm{CTO} \mathrm{PCl}$ as a proportion of total for each centre

\begin{tabular}{lllcl}
\hline Centre & $\begin{array}{l}\text { Total PCls } \\
\text { pre-proctored/ } \\
\text { non-proctored }\end{array}$ & $\begin{array}{l}\text { Pre-proctored/ } \\
\text { non-proctored } \\
\text { CTO PCls attempted }\end{array}$ & $\begin{array}{l}\text { Total PCls } \\
\text { post-proctored }\end{array}$ & $\begin{array}{l}\text { Post-proctored } \\
\text { CTO PCls attempted }\end{array}$ \\
\hline Centre 1 & 2633 & $29(1.1 \%)$ & 2170 & $28(1.3 \%)$ \\
Centre 2 & 2756 & $82(3 \%)$ & 2681 & $130(4.8 \%)$ \\
Centre 3 & 589 & $(2$ operators) & $(2$ operators) \\
Centre 4 & 878 & $13(2.2 \%)$ & 1403 & $47(3.3 \%)$ \\
Centre 5 & $15(1.7 \%)$ & 871 & $17(2 \%)$ \\
Centre 6 & 498 & $(1$ operator) & $(10 p e r a t o r)$ \\
All centres & 8734 & $36(2.6 \%)$ & 2061 & $74(3.6 \%)$ \\
\hline CTO, chronic total occlusion; PCl, percutaneous coronary intervention. & $59(6 \%)$ \\
\end{tabular}

the subgroup of retrograde procedures. The theoretical knowledge from meetings and equipment was already in place before proctoring started. After proctoring, use of the retrograde approach increased threefold from $9.5 \%$ to $29.9 \%$ along with a significant increase in retrograde success from $36 \%$ to $59 \%$.

While success rates of $78 \%$ cannot compare with the best reported series from expert operators, ${ }^{7}$ we have identified a $16 \%$ absolute increase in success over a median period of 7 months. The annual increase in success of $0.4 \%$ reported by BCIS audit figures would suggest that operators might work their entire careers relying on experiential learning and specialist meetings without achieving the same increase in success demonstrated after three visits from a proctor.

CTO PCI involves progression through a number of discrete steps. The later stages (RDR, externalisation, re-entry with Stingray system) can only be attempted after success of the preceding stages (retrograde access, successful crossing with knuckle wire or CrossBoss catheter).

\begin{tabular}{|c|c|c|}
\hline Complications & $\begin{array}{l}\text { Pre-proctored/ } \\
\text { non-proctored }\end{array}$ & Post-proctored \\
\hline Coronary & $10(4.3 \%)$ & $13(3.7 \%)$ \\
\hline Ventricular fibrillation & $1(0.4 \%)$ & $0(0 \%)$ \\
\hline $\begin{array}{l}\text { Femoral access } \\
\text { haematoma }\end{array}$ & $1(0.4 \%)$ & $4(1.1 \%)$ \\
\hline Aorto-ostial dissection & $2(0.9 \%)$ & $1(0.3 \%)$ \\
\hline Side branch occlusion & $0(0 \%)$ & $2(0.6 \%)$ \\
\hline $\begin{array}{l}\text { Donor vessel } \\
\text { thrombosis }\end{array}$ & $0(0 \%)$ & $1(0.3 \%)$ \\
\hline Retroperitoneal bleed & $0(0 \%)$ & $4(1.1 \%)$ \\
\hline Death & $1(0.4 \%)$ & $2(0.6 \%)$ \\
\hline $\begin{array}{l}\text { Transient ischaemic } \\
\text { attack }\end{array}$ & $0(0 \%)$ & $1(0.3 \%)$ \\
\hline Femoral dissection & $0(0 \%)$ & $1(0.3 \%)$ \\
\hline Total & $15 / 232(6.5 \%)$ & $30 / 354(8.5 \%)$ \\
\hline
\end{tabular}

The presence of a proctor to guide or even personally undertake a particularly challenging stage enables the case to progress safely to the point when experience can be gained on the final stages.

If a case fails at an earlier stage, this experience in the later stages is lost and a greater number of cases are required for competency in the later stages to be reached.

AWE success accounted for a lower proportion of successful procedures after proctoring. One explanation might be that proctored operators were looking for opportunities to use new techniques and technologies, when a simpler strategy could have been successful if given more time. While our data cannot disprove this, we believe a more likely explanation may lie in the differences in case mix, with a greater number of previous failures and post-CABG patients in the post-proctored group. These factors suggest a greater technical complexity and a lower likelihood of success with AWE.

The proportion of cases treated successfully by AWE was $57 \%$ before proctoring and $48 \%$ after proctoring. This compares to $50 \%$ of cases successfully completed by AWE in the US Hybrid registries. ${ }^{11}$ This proportion falls lower still in case series where there is a higher proportion of difficult cases. ${ }^{7}$ In this series (where the proportion of cases with JCTO score $\geq 2$ was $89 \%$ ) only $34 \%$ of successful cases were treated by AWE.

\section{Limitations}

There are a number of potential limitations with this study. Validation of CTOs, assessment of success and calculation of JCTO score has been undertaken in the centre where PCI was performed rather than at a single core laboratory. Nevertheless, a single observer, independent to the operator, was responsible for angiographic analysis and data collection of pre-proctored and post-proctored data in each centre. As a retrospective study, we have relied on routine clinical data collection to capture complications, which may therefore be under-reported. We cannot control for operators deferring treatment of 'ideal' cases until after appropriate 
'training had been received', but we believe this is unlikely as the most favourable cases were generally selected as 'training' cases when the proctors visited. Our attempt to assess the impact of proctorship on the revascularisation rates of patients with CTOs is limited as we do not have validated CTO data from non-proctored operators from every centre. We will, therefore, have underestimated the overall CTO PCI 'rate' but believe the relative increase that we observe following proctorship to be valid.

\section{Summary}

We have demonstrated that proctoring results in an increase in procedural success, an increase in complex CTO PCI activity and a small increase in overall CTO PCI activity. We believe that existing expert PCI operators wishing to undertake CTO PCI will see significantly better results following further formal training and, in particular, undertaking cases jointly with a visiting proctor in their own centre. Proctoring may be a valuable way to improve access to CTO PCI and the likelihood of procedural success for patients.

\author{
Author affiliations \\ ${ }^{1}$ Trent Cardiac Centre, Nottingham City Hospital, Nottingham, UK \\ ${ }^{2}$ The Essex Cardiothoracic Centre, Essex, UK \\ ${ }^{3}$ Freeman Hospital, Newcastle upon Tyne, UK \\ ${ }^{4}$ Golden Jubilee National Hospital, Clydebank, UK \\ ${ }^{5}$ Royal Bournemouth Hospital, Bournemouth, UK \\ ${ }^{6}$ Forth Valley Royal Hospital, Larbert, UK \\ ${ }^{7}$ Bristol Royal Infirmary, Bristol, UK \\ ${ }^{8}$ Belfast City Hospital, Belfast, UK
}

Contributors VS, STJ, AAH and WHTS contributed to the conception and design of the work, the acquisition, analysis and interpretation of data from the first centre and overall data; drafting the work or revising it critically for important intellectual content; final approval of the version published. Agreement to be accountable for all aspects of the work in ensuring that questions related to the accuracy or integrity of any part of the work are appropriately investigated and resolved. In addition, WHTS is the corresponding author. PAK and AM contributed to the conception and design of the work, the acquisition, analysis and interpretation of data (second centre); drafting the work or revising it critically for important intellectual content; final approval of the version published. Agreement to be accountable for all aspects of the work in ensuring that questions related to the accuracy or integrity of any part of the work are appropriately investigated and resolved. $A B, J R$ and $M E$ contributed to the conception and design of the work, the acquisition, analysis and interpretation of data (third centre); drafting the work or revising it critically for important intellectual content; final approval of the version published. Agreement to be accountable for all aspects of the work in ensuring that questions related to the accuracy or integrity of any part of the work are appropriately investigated and resolved. MM, AS and KO contributed to the conception and design of the work, the acquisition, analysis and interpretation of data (fourth centre); drafting the work or revising it critically for important intellectual content; final approval of the version published. Agreement to be accountable for all aspects of the work in ensuring that questions related to the accuracy or integrity of any part of the work are appropriately investigated and resolved. GV, OR and ST contributed to the conception and design of the work, the acquisition, analysis and interpretation of data (fifth centre); drafting the work or revising it critically for important intellectual content; final approval of the version published. Agreement to be accountable for all aspects of the work in ensuring that questions related to the accuracy or integrity of any part of the work are appropriately investigated and resolved. MM and JWS contributed to the conception and design of the work, the acquisition, analysis and interpretation of data (sixth centre); drafting the work or revising it critically for important intellectual content; final approval of the version published. Agreement to be accountable for all aspects of the work in ensuring that questions related to the accuracy or integrity of any part of the work are appropriately investigated and resolved. CGH, SJW and JCS contributed to the conception and design of the work, the acquisition, analysis and interpretation of overall data; drafting the work or revising it critically for important intellectual content; final approval of the version published. Agreement to be accountable for all aspects of the work in ensuring that questions related to the accuracy or integrity of any part of the work are appropriately investigated and resolved. In addition all three authors were the proctors involved in training the operators.

Competing interests $A B$, Honoraria/grants from Abbott, Biosensors, Boston Scientific and Medtronic. ME, Honoraria/proctorship from Abbott, Boston Scientific, Spectranetics, Vascular Perspectives, Volcano. ST, Honoraria/grants from Abbott, Boston Scientific, Biosensors and Spectranetics. JWS,

Consultant to Abbott, Boston Scientific. CGH, Proctor to Boston Scientific. SJW, Consultant to Abbott, Biosensors and Boston Scientific. JCS, Consultant to Abbott, Biosensors and Boston Scientific.

Ethics approval Local Audit Committee.

Provenance and peer review Not commissioned; externally peer reviewed.

Data sharing statement No additional data are available.

Open Access This is an Open Access article distributed in accordance with the Creative Commons Attribution Non Commercial (CC BY-NC 4.0) license, which permits others to distribute, remix, adapt, build upon this work noncommercially, and license their derivative works on different terms, provided the original work is properly cited and the use is non-commercial. See: http:// creativecommons.org/licenses/by-nc/4.0/

\section{REFERENCES}

1. Patel VG, Brayton KM, Tamayo A, et al. Angiographic success and procedural complications in patients undergoing percutaneous coronary chronic total occlusion interventions: a weighted meta-analysis of 18,061 patients from 65 studies. JACC Cardiovasc Interv 2013;6:128-36.

2. Syrseloudis D, Secco GG, Barrero EA, et al. Increase in J-CTO lesion complexity score explains the disparity between recanalisation success and evolution of chronic total occlusion strategies: insights from a single-centre 10-year experience. Heart 2013;99:474-9.

3. Fefer $\mathrm{P}, \mathrm{Knudts}$ ( ML, Cheema AN, et al. Current perspectives on coronary chronic total occlusions: the Canadian Multicenter Chronic Total Occlusions Registry. J Am Coll Cardiol 2012;59:991-7.

4. Morino $\mathrm{Y}, \mathrm{Abe} \mathrm{M}$, Morimoto $\mathrm{T}$, et al. J-CTO Registry Investigators. Predicting successful guidewire crossing through chronic total occlusion of native coronary lesions within 30 minutes: the J-CTO (Multicenter CTO Registry in Japan) score as a difficulty grading and time assessment tool. JACC Cardiovasc Interv 2011;4:213-21.

5. Rinfret S, Joyal D, Nguyen CM, et al. Retrograde recanalization of chronic total occlusions from the transradial approach; early Canadian experience. Catheter Cardiovasc Interv 2011;78:366-74.

6. Brilakis ES, Grantham JA, Rinfret S, et al. A percutaneous treatment algorithm for crossing coronary chronic total occlusions. JACC Cardiovasc Interv 2012;5:367-79.

7. Pershad A, Eddin M, Girotra S, et al. Validation and incremental value of the hybrid algorithm for CTO PCI. Catheter Cardiovasc Interv 2014;84:654-9.

8. Grantham JA, Marso SP, Spertus J, et al. Chronic total occlusion angioplasty in the United States. JACC Cardiovasc Interv 2009;2:479-86.

9. Michael TT, Karmpaliotis D, Brilakis ES, et al. Impact of prior coronary artery bypass graft surgery on chronic total occlusion revascularisation: insights from a multicentre US registry. Heart 2013;99:1515-18.

10. Smith EJ, Strange JW, Hanratty CG, et al. Percutaneous intervention for chronic total occlusion: integrating strategies to address an unmet need. Heart 2013;99:1471-4.

11. Michael TT, Karmpaliotis D, Brilakis ES, et al. Procedural outcomes of revascularization of chronic total occlusion of native coronary arteries (from a multicenter United States registry). Am J Cardiol 2013;112:488-92. 